\title{
Humanização em saúde: da alienação em Marx às micropolíticas
}

\author{
Humanization in health: from Marx's alienation \\ to micropolitics
}

\author{
Humanización en salud: de la alienación en Marx \\ a las micropolíticas
}

\author{
HUMANIZAÇÃO E DESUMANIZAÇÃO NO \\ TRABALHO EM SAÚDE. Gomes RM. Rio de \\ Janeiro: Editora Fiocruz; 2017. 312 p. ISBN \\ 978-85-7541-491-0.
}

doi: 10.1590/0102-311X00028219

No livro Humanização e Desumanização no Trabalho em Saúde, publicado em 2017 pela Editora Fiocruz, Rogério Miranda Gomes discute as práticas médicas atuais e suas transformações que refletem e, ao mesmo tempo, fundam o trabalho no campo da saúde, produzindo ações desumanizadoras.

A humanização em saúde é discutida a partir do olhar para o percurso histórico do médico como analisador importante das práticas em saúde e de como o processo saúde/doença foi sendo produzido.

Essa análise é feita de forma ampliada, tendo como conceito condutor a alienação marxista, que coloca em cena a capacidade criadora do homem, mas também o processo de expropriação de sua criação, produzindo perda de autonomia e restrição em seu viver.

E esse processo de alienação nos é apresentado no cruzamento de dois importantes fenômenos históricos - a transição da medicina liberal para a medicina técnica e a transição epidemiológica.
Por um lado, a Medicina se socializa e se mercantiliza, se hierarquiza e se especializa, distanciando-se da relação com o usuário. Por outro, a ampliação de condições crônicas de adoecimento e a medicalização social impactam na relação de cuidado estabelecida e nas representações do médico. O autor aponta para uma desconstrução do papel de salvador vivenciado e, muitas vezes, enaltecido pelo médico, para um lugar de conservador e ajustador.

E um descompasso é instalado, pois as condições atuais de sofrimento exigem relações mais cuidadoras e integrais enquanto o trabalho em saúde vai se construindo de forma fragmentada e impessoal, com base em relações de consumo cada vez mais exploratórias e mercantilistas. O usuário atualmente assume esse lugar de consumidor e cidadão, colocando-se na relação de forma mais ativa e questionadora. Podemos aí destacar o processo de ampliação de acesso à informação com a Internet e redes sociais, assim como a judicialização na saúde, com a interferência do judiciário nas decisões dentro do sistema de saúde.

Assim, a alienação se mostra na ausência de problematização sobre os determinantes sociais dos sofrimentos a serem cuidados, assim como também na relação com os recursos terapêuticos a serem utilizados, que no caso dos médicos é revelada em sua relação com as indústrias farmacêuticas e de equipamentos médicos. Outro recurso analisado pelo autor é o uso de proto- 
colos e auditorias como forma de normatizar o trabalho em saúde.

Uma ultravalorização da tecnologia aparece como imagem máxima da alienação e media a relação entre o médico e o usuário. Assim, essa relação se transforma com interferências na confiança antes depositada no médico. Podemos dizer que esse efeito atravessa as relações de forma ampliada, podendo ser associado e intensificado pela rede virtual com suas fake news.

Segundo o autor, tal cenário impõe ao médico, como analisador das práticas em saúde, a necessidade de construção de encontros com o usuário mais transparentes e participativos, em que a relação possa ser construída de forma mais democrática e solidária. Porém, ele alerta para o risco dessa abertura não transformar o caráter instrumental desse encontro.

Nessa linha, Cecílio ${ }^{1}$ ratifica a importância desse momento de encontro com o usuário ao pensar o cuidado baseando-se em três dimensões imanentes: profissional, organizacional e sistêmica. Destacamos a dimensão profissional que é onde acontece o sempre singular encontro entre trabalhador e usuário, espaço de responsabilidade e liberdade do trabalhador. A dimensão organizacional é aquela na qual a responsabilidade gerencial e a conformação da dinâmica de relacionamento da equipe ocupam lugar central. E a dimensão sistêmica engloba o conjunto de serviços de saúde, com suas diferenças e fluxos estabelecidos entre si.

Diante disso, podemos dizer que o autor, com base em uma análise histórico-social da prática médica, nos coloca questões importantes a serem pensadas no campo da saúde. Porém, mesmo sabendo-se que esse modelo biomédico ainda marca as práticas em saúde, seria interessante o aprofundamento de outro pensar a saúde que já se coloca em cena, compondo o jogo de forças nos serviços de saúde, tanto na atenção quanto na gestão em saúde.

Azevedo et al. 2 nos apresentam essas duas tendências, sendo que uma baseia-se na racionalização das práticas médico-hospitalares por meio da qualificação, padronização e controle dos processos de trabalho e que se expressam nas práticas de Acreditação e Contratualização, e outra baseada na modernização gerencial do hospital valendo-se de uma perspectiva mais dialógica e comunicativa.

Essa apoia-se na mobilização dos coletivos de trabalho em torno de um projeto de qualificação da atenção, com ênfase nos aspectos microssociais e relacionais/intersubjetivos. Valoriza, ainda, a ampliação da clínica e a centralidade do sujeito nas práticas de saúde.

Sendo assim, entendendo a relação de oposição, mas também de complementariedade entre humanização e alienação, podemos dizer que esta se refletirá com base no grau de exercício desses modelos de atenção e gestão nos serviços de saúde, com ênfase maior em práticas gerencialistas e normatizadoras ou práticas mais participativas e democráticas que permitam a participação e construção coletivas.

Tal olhar nos permite pensar não numa lógica de oposição entre tais tendências, mas buscando ressignificar os diversos processos de controle, padronização e monitoramento presentes e necessários ao trabalho em saúde, assim como sua forma de construção nos serviços e apropriação pela equipe de saúde. Ressignificar o modo de fazer, de forma que tais processos tenham sentido para os diversos atores envolvidos e também produzam sentido para o trabalho em saúde ${ }^{3}$.

Nesse rastro, destaca-se um modo de pensar e de fazer a gestão e a atenção em saúde que tem como elemento central a defesa da vida na sua possibilidade de criação constante. Essas ideias dialogam com os processos de qualificação e possibilitam seu redesenho.

A Política Nacional de Humanização da Atenção e Gestão do SUS (PNH) 4 com seus princípios que marcam diversas outras políticas instauradas no Ministério da Saúde, ao olhar para as experiências do "SUS que dá certo", aponta algumas diretrizes e dispositivos para se repensar o trabalho em saúde. Essa coloca como princípio a inclusão dos diversos atores que participam desse campo (gestor, trabalhador e usuário), dialogando de forma transversal e intersetorial, e 
entendendo que as alterações provocadas na forma de se fazer gestão produzem sujeitos e interferem no cuidado produzido e ofertado.

Assim, destaco as questões apontadas pelo autor associadas a uma leitura das micropolíticas como necessárias para a formação em saúde, com foco na produção de um projeto de atenção integral e de gestão democrática, construída de forma interdisciplinar e multisetorial, como um caminho necessário de interferência nas práticas de saúde atuais.

\section{Andreia Maria Thurler Fontoura ${ }^{1}$}

1 Instituto Nacional de Saúde da Mulher, da Criança e do Adolescente Fernandes Figueira, Fundação Oswaldo Cruz, Rio de Janeiro, Brasil.

andthurler@hotmail.com

\section{Informação adicional}

ORCID: Andreia Maria Thurler Fontoura (0000-

0002-3438-6648).
1. Cecilio LCO. A morte de Ivan Ilitch, de Leon Tolstói: elementos para se pensar as múltiplas dimensões da gestão do cuidado. Interface Comun Saúde Educ 2009; 13 Suppl 1:545-55.

2. Azevedo CS, Sá MC, Miranda L, Grabois V. Caminhos da organização e gestão do cuidado em saúde no âmbito hospitalar brasileiro. Revista de Política, Planejamento e Gestão em Saúde 2010; 1:95-115.

3. Santos-Filho SB. Perspectivas da avaliação na Política Nacional de Humanização em Saúde: aspectos conceituais e metodológicos. Ciênc Saúde Colet 2007; 12:999-1010.

4. Secretaria de Atenção à Saúde, Ministério da Saúde. Política Nacional de Humanização da Atenção e Gestão do SUS. Documento base. Brasília: Ministério da Saúde; 2010. 